\title{
Quasi-Dimensional Modeling of a CNG Fueled HCCI Engine Combustion Using Detailed Chemical Kinetic
}

\author{
Y. Bakhshan ${ }^{1 \dagger}$ and A. H. Shadaei ${ }^{2}$ \\ ${ }^{1}$ Department of Mechanical Engineering, University of Hormozgan, Hormozgan, 3990, Iran \\ ${ }^{2}$ Department of Mechanical Engineering, University of Hormozgan, Hormozgan, 3990, Iran
}

$\dagger$ Corresponding Author Email: bakhshany@yahoo.com

(Received July 19, 2011; accepted October 22, 2011)

\begin{abstract}
In this study, an in-house quasi dimensional code has been developed which simulates the intake, compression, combustion, expansion and exhaust strokes of a homogeneous charge compression ignition (HCCI) engine. The compressed natural gas (CNG) has been used as fuel. A detailed chemical kinetic scheme constituting of 310 and 1701 elementary equations developed by Bakhshan et al. has been applied for combustion modeling and heat release calculations. The zero-dimensional k- $\varepsilon$ turbulence model has been used for calculation of heat transfer. The output results are the performance and pollutants emission and combustion characteristics in HCCI engines. Parametric studies have been conducted to discussing the effects of various parameters on performance and pollutants emission of these engines.
\end{abstract}

Keywords: HCCI, quasi dimensional, detailed chemical kinetic, CNG, simulation, $\mathrm{k}-\varepsilon$

\section{NOMENCLATURE}

$\begin{array}{ll}A & \text { amplification (RDT) } \\ C_{P} & \text { SH at Const. Pressure } \\ C_{\beta} & \text { adjustable constant } \\ E & \text { activation energy } \\ h & \text { enthalpy } \\ i & \text { mixture species index } \\ j & \text { inlet and outlet species index } \\ K & \text { mean KE } \\ k & \text { turbulent KE, reaction rates } \\ k & \text { species index } \\ \ell & \text { integral length scale } \\ m & \text { mass } \\ o & \text { denotes reference condition } \\ P & \text { cylinder gas pressure } \\ P & \text { turbulent energy prod }\end{array}$

\section{INTRODUCTION}

Homogeneous Charge Compression Ignition (HCCI) engines are considered to be a new generation of internal combustion engines that operate on the basis of auto-ignition and provide a higher thermal efficiency and lower exhaust pollutants compared to the present classic versions and is perceived as an engine for future power trains which will provide improved fuel

$\begin{array}{ll}q & \text { progress variable } \\ R & \text { gas constant } \\ s & \text { entropy } \\ T & \text { temperature } \\ U & \text { mean cylinder velocity } \\ u^{\prime} & \text { turbulent velocity } \\ v & \text { specific volume } \\ W_{m w} & \text { molecular weight } \\ Y & \text { mass fraction species } \\ \omega^{0} & \text { chemical production rate } \\ \rho & \text { density } \\ v & \text { stoichiometric coefficient } \\ \varepsilon & \text { eddy dissipation } \\ \mu_{t} & \text { turbulent viscosity }\end{array}$

efficiency and lower emissions at the same time and was identified as a distinct combustion phenomenon about 20 years ago. In HCCI mode, a mixture of air and fuel is compressed, by increasing the gas temperature and pressure so, the auto ignition of the fuel occurs. The advantage of this process is that the combustion occurs simultaneously in the entire combustion chamber under lean conditions. The maximum combustion temperatures are thus reduced to levels below the NOx 
formation threshold. Due to the nearly homogeneous and lean mixture, soot forming fuel-rich combustion is also avoided. Application of advanced combustion technologies for optimization of combustion systems is increasing due to limitation of fossil fuel resources. Initial papers (Onishi et al. (1979)) recognized the basic characteristics of HCCI that have been validated many times and in this engine HCCI ignition occurs at many points simultaneously, with no flame propagation and combustion was described as very smooth with very low cyclic variation. Noguchi et al. (1979) conducted a spectroscopic study of HCCI combustion and many radicals were observed, and they were shown to appear in a specific sequence. In contrast, with spark-ignited (SI) combustion all radicals appear at the same time, spatially distributed through the flame front. These initial HCCI experiments were done in 2-stroke engines with low compression ratio and very high EGR. Najt and Foster (1983) were first to run a four-stroke engine in HCCI mode and they also analyzed the process, considering that HCCI is controlled by chemical kinetics, with negligible influence of physical effects (turbulence mixing).They used a simplified chemical kinetics model to predict heat release as a function of pressure, temperature, and species concentrations in the cylinder. Unfortunately, HCCI has several problems that have limited its commercialization specifically, it is very difficult to control the initiation and rate of combustion over the required speed and load range of that engine (Ryan and Cahhahan (1996)). This is important at higher loads where very rapid pressure rise and knock are limiting. HCCI engines also operate at lower combustion temperatures, so more unburned hydrocarbons (UHC) and $\mathrm{CO}$ emissions are generated than in traditional engines and some of these disadvantages may be reduced or eliminated by operating these engines in "hybrid mode," where the engine operates in HCCI mode at low power and in spark-ignited mode (Ishibashi and Asai 1996), or diesel mode (Kimura et al. (1999)), at high power. This hybrid mode takes advantage of high efficiency and low NOx and particulate matter emissions of HCCI engines at low power conditions. Engine design is a time consuming process in which many costly experimental tests are normally conducted, and the expense of optimizing engine designs is even more costly (Ritz et al. 2004, Yao et al. 2007, Kee et al. 1996 and Pascal 2011. With increasing prediction ability of engine simulation tools, engine design aided by relatively low cost CFD modeling is becoming more popular in both industry and academia. In an effort to include the best representation of both fluid flow and chemical kinetics, attempts have been made to use three-dimensional CFD models coupled directly with chemical kinetics to study compression ignition under HCCI like-conditions. Agarwal and Assanis (1998) reported on the coupling of a detailed chemical kinetic mechanism for natural gas ignition (22 species and 104 elementary reactions) with the multi-dimensional reacting flow code and explored the auto-ignition of natural gas injected in a quiescent chamber under diesel like conditions. Kong et al. (2002) proposed a similar approach up to the point of ignition, while after ignition they introduced a reaction rate incorporating the effects of both chemical kinetics and turbulent mixing through characteristic timescales. Hong et al. (2002) proposed a more computationally demanding model to simultaneously account for the effects of detailed chemistry and mixing on ignition delay within the KIVA-3V CFD code. In this study, an in-house quasi dimensional code has been developed which simulates the processes occurred in a HCCI engine fueled with CNG.A detailed chemical kinetic scheme developed by Bakhshan and Shahrir (2009) constituting of 1701 elementary reactions and 310 species and with its modifying to CHEMKIN format, has been used. Also chemical kinetic scheme used here, involves the reactions required for calculation of $\mathrm{NO}_{\mathrm{X}}$. The zero-dimensional- $\varepsilon$, turbulence model developed by Bakhshan and Mansouri (2000) has been modified and applied for calculation of effective velocity and heat transfer from $\mathrm{HCCI}$ engine.

\section{MODEL FORMULATION}

\subsection{Conservation of Mass}

The rate of change of mass within any open system is the net flux of mass across the system boundaries.

$$
\frac{d m}{d t}=\sum_{j} \dot{m}_{j}
$$

Where the subscript ' $\mathrm{j}$ ' refers to each of the component species present in the mixture and $\{\mathrm{m}\}$ denotes the total mass within the control cylinder.

\subsection{Conservation of Species}

The species equations are deduced from their multidimensional counterparts by neglecting species diffusion terms, consistent with the zero-dimensional assumption, and we have:

$\dot{y}_{i}=\sum\left(\frac{\dot{m}_{j}}{m}\right)\left(y_{i}^{j}-y_{i}^{c y l}\right)+\frac{\dot{\omega} W_{M W}}{\rho}$

\subsection{Conservation of Energy}

From the general energy equation for an open thermodynamic system, with a assumption a single phase, multi-component mixture of ideal gases, and ideal gas low,

$$
\begin{aligned}
& \dot{P}=P\left[\frac{\sum R_{i} \dot{y}_{i}}{R}+\frac{\dot{m}}{m}+\frac{\dot{T}}{T}-\frac{\dot{V}}{V}\right] \\
& \dot{T}=\frac{1}{A}\left[-\left(\sum h_{i}-\frac{P v \sum R_{i}}{R}\right) \dot{y}_{i}-\frac{\dot{m}}{m} B\right. \\
& \left.+\frac{1}{m}\left(\sum \dot{m}_{j} h_{j}-P \dot{V}+\dot{Q}\right)\right]
\end{aligned}
$$

where $A=\bar{C}_{F}-\frac{F_{\mathrm{T}}}{T}$ and $B=\bar{h}_{-}-P_{V}$.

\subsection{Reactions Formulation}

Since detailed chemical kinetics will be used to simulate the fuel oxidation, a detailed chemical kinetic 
scheme developed by Bakhshan and Shahrir (2009) constituting of 1701 elementary reactions and 310 species and modified it to CHEMKIN format has been coupled to our developed code to calculating the species concentrations during simulation. The formulations of chemical kinetics are as blow;

$$
\begin{aligned}
& \sum_{k=1}^{K} v_{k i}^{\prime} \chi_{k} \Leftrightarrow \sum_{k=1}^{K} v_{k i}^{\prime \prime} \chi_{k} \\
& \dot{\omega}_{k}=\sum_{i=1}^{I} v_{k i} q_{i}
\end{aligned}
$$

Where

$$
\begin{aligned}
& v_{k i}=v_{k i}^{\prime \prime}-v_{k i}^{\prime} \\
& q_{i}=\left(\sum_{k=1}^{K} a_{k i}\left[X_{k}\right]\right)\left(k_{f i} \prod_{k=1}^{K}\left[X_{k}\right]^{v_{k i}^{\prime}}-k_{r i} \prod_{k=1}^{K}\left[X_{k}\right]^{v_{k i}^{\prime \prime}}\right) \\
& {[M]=\sum_{k=1}^{K}\left[X_{k}\right]} \\
& k=A T^{b} e^{-E / R_{u} T}
\end{aligned}
$$

\subsection{Thermodynamic Properties Treatment}

The thermodynamic property treatment will employ the NASA curve-fits for specific heat, enthalpy, and entropy,

$$
\begin{aligned}
& \frac{C_{P k}^{o}}{R}=\sum_{n=1}^{5} a_{n k} T^{n-1} \\
& \frac{h_{k}^{o}}{R T_{k}}=a_{1 k}+\sum_{n=1}^{5} \frac{a_{n, k}}{n} T_{k}^{n-1}+\frac{a_{6 k}}{T_{k}} \\
& \frac{s_{k}^{o}}{R}=a_{1 k} \ln \left(T_{k}\right)+\sum_{n=1}^{4} \frac{a_{n+1, k}}{n} T_{k}^{n}+a_{7 k}
\end{aligned}
$$

The parameters used in above equations are discussed in nomenclature.

\subsection{Heat Transfer Model}

The zero-dimensionalk- $\varepsilon$ turbulence model given by Bakhshan and Mansouri (2000) is used for calculating the characteristics velocity and heat ransfer and the detail of formulation can be found in the published papers by Mansouri and Bakhshan(2000,2001).

$$
\begin{aligned}
& K=\frac{1}{2} m U^{2} \\
& k=\frac{3}{2} m u^{\prime} \\
& \frac{d K}{d t}=\frac{1}{2} \dot{m}_{i} V_{i}^{2}-\mathrm{P}-K \frac{\dot{m}_{e}}{m_{e}} \\
& \frac{d k}{d t}=\mathrm{P}-m \varepsilon-k \frac{\dot{m}_{e}}{m}+\mathrm{A} \\
& \varepsilon \approx u^{\prime 3} / \ell=(2 k / 3 m)^{3 / 2} / \ell \\
& \mathrm{A}=\frac{2}{3} k \frac{\dot{\rho}}{P} \\
& \ell=L=\frac{V}{\left(\pi B^{2} / 4\right)}
\end{aligned}
$$

$$
\mathrm{P}=0.3307 c_{B}\left(\frac{K}{L}\right)\left(\frac{k}{m}\right)^{1 / 2}
$$

The chimical kinetic scheme use here, consist of 1701 elementary reactions and 310 species and the reactions required for calculation of Nox from extended Zeldovich mechanism. The general algorithm of code is shown in Fig.1.

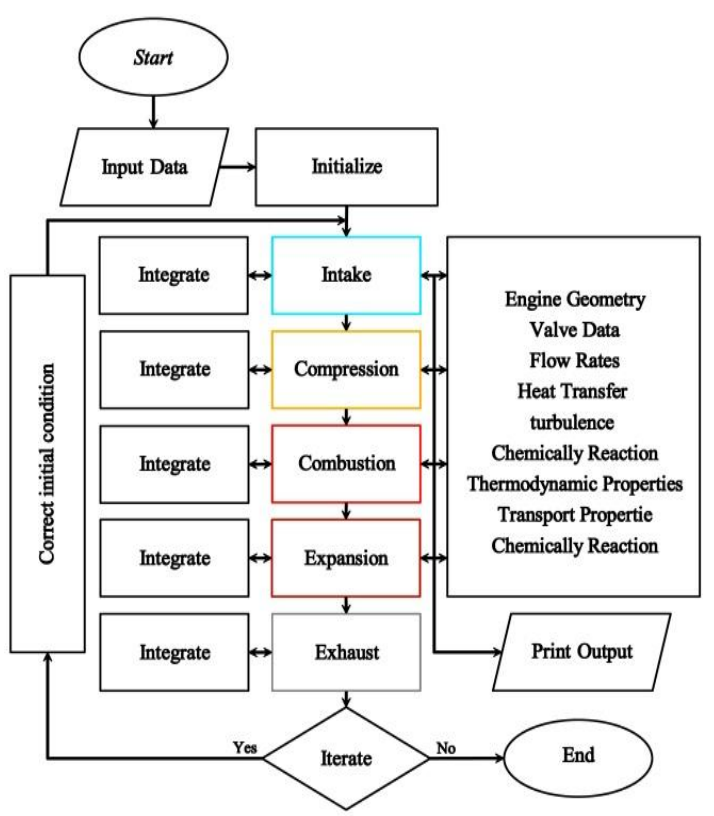

Fig.1. Code Flowchart

\section{RESUlTS AND Discussions}

The engine specifications and operation conditionsused in this simulation and operating conditions for base engine,are shown in Table 1 and Table 2.The fuel considered here is compound of methane, buthane, propane and other gases according to Table 2.

The calculation was carried out throughout a thermodynamic cycle and for validation of simulation results, the computed in-cylinder pressure has been compared with experimental data and are shown in Fig. 2 and Fig. 3.The comparison shows good agreement between the simulation results and experimental data and this means, the constructed model and the coupled detailed chemical kinetic scheme have good accuracy and can be used as a tool in calculation of other paparameters in continuation.

Table 1 Engine Specifications

\begin{tabular}{ll}
\hline EngineFeature & Specification \\
\hline Bore & $12.065 \mathrm{Cm}$ \\
\hline Stroke & $14 \mathrm{Cm}$ \\
\hline Connecting Rod Length & $160 \mathrm{~mm}$ \\
\hline Compression Ratio & 19.8 \\
\hline Intake Valve Open & $5^{\circ}$ ATDC \\
\hline Intake Valve Close & $13^{\circ}$ ABDC \\
\hline Exhaust Valve Open & $39^{\circ}$ BBDC \\
\hline Exhaust Valve Close & $10^{\circ}$ BTDC \\
\hline
\end{tabular}


Table 2 Operating conditions for base engine

\begin{tabular}{|c|c|c|}
\hline $\begin{array}{l}\text { Intake Manifold Pressure } \\
\text { (absolute) }\end{array}$ & $1 \mathrm{~atm}$ & \\
\hline $\begin{array}{ll}\text { Intake } & \text { Manifold } \\
\text { Temperature } & \\
\end{array}$ & $130^{\circ} \mathrm{C}$ & \\
\hline Initial Wall Temperature & $130^{\circ} \mathrm{C}$ & \\
\hline Equivalence Ratio & 0.3 & \\
\hline Engine Speed (RPM) & 1000 & \\
\hline Fuel & $\begin{array}{l}\mathrm{CH} 4 \\
\mathrm{C} 2 \mathrm{H} 6 \\
\mathrm{C} 3 \mathrm{H} 8 \\
\mathrm{C} 4 \mathrm{H} 10 \\
\text { IC4H10 } \\
\mathrm{NC} 5 \mathrm{H} 12 \\
\mathrm{~N} 2 \\
\mathrm{CO} 2\end{array}$ & $\begin{array}{r}87.15 \% \\
6.93 \% \\
3.11 \% \\
0.63 \% \\
0.44 \% \\
0.23 \% \\
0.32 \% \\
1.19 \%\end{array}$ \\
\hline
\end{tabular}

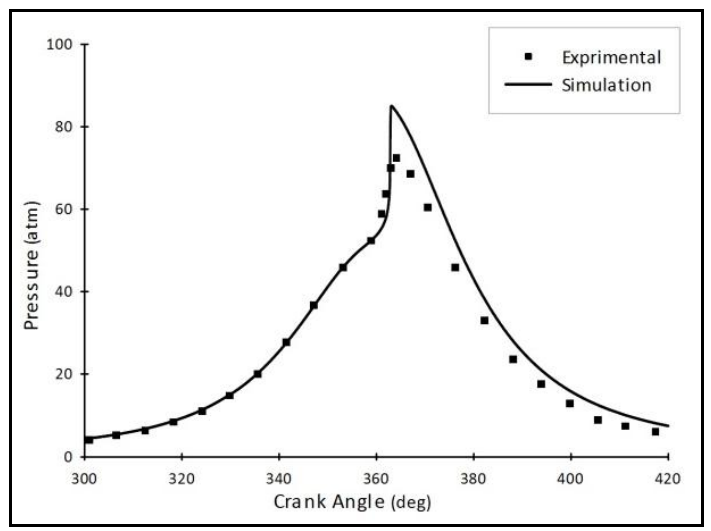

Fig. 2. Comparison of the simulated and measured cylinder pressure

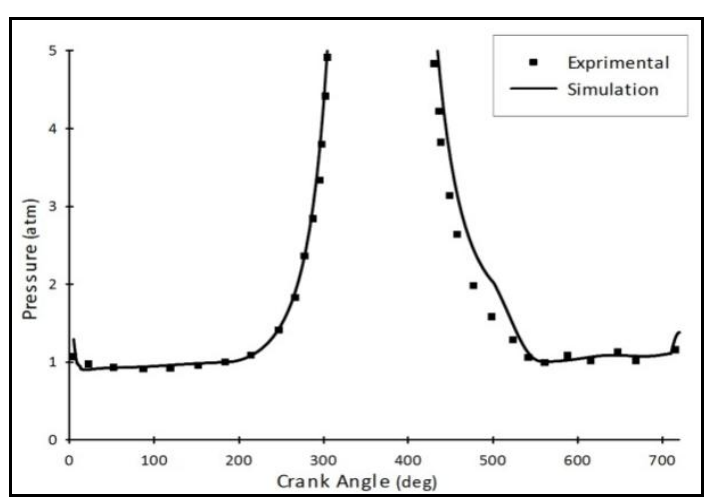

Fig. 3. Comparison of measured and predicted cylinder pressure during gas exchange processes

After validation of constructed code, the results have been extracted for a base engine which has capability to change to HCCI engine. Figures 4 and 5 show the pressure and temperature variation during a thermodynamic cycle and contains the all processes occurred in internal combustion engine. (Intake, compression, combustion, expansion and exhaust).The operating conditions have been chosen to onset the combustion in the cylinder and this is shown in Fig. 4 and Fig. 5, because in HCCI engine there is not spark and combustion is started with chemical kinetic so, the rapid increasing of pressure and temperature shows the starting of combustion. The heat transfer has been modelled with using the zero- dimensional K-عturbulence modeled suggested by Bakhshan and Mansouri (2000). It has good capability with HCCI engine operating condition because constants in the model can be modified to adjust the experimental data with calculation results; however the variation of heat transfer rate with crank angle is shown in Fig. 6. The heat transfer increases in the compression stroke due to increasing the velocity of in-cylinder fluid and its rate has the highest value at this stroke. Also the rate of heat transfer has a mini-peak value in exhaust stroke, because when the exhaust valve opens, due to high pressure difference between inlet and outlet of cylinder, the velocity of the products at inlet of cylinder increases and thus the heat transfer rate takes high values.

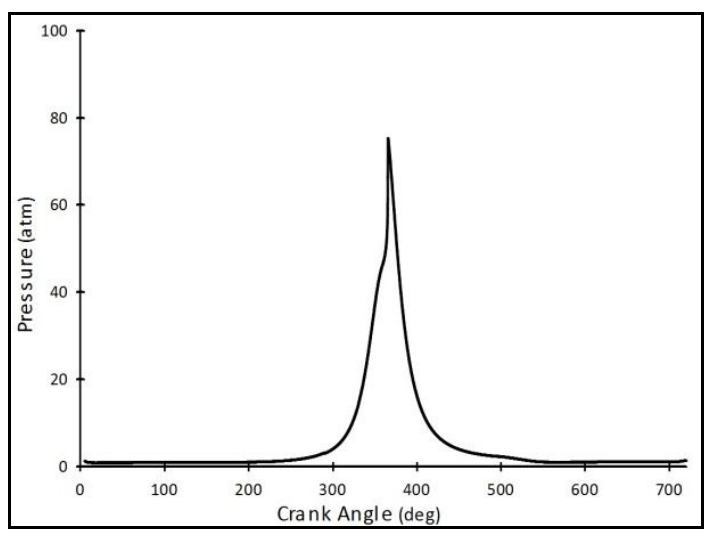

Fig. 4. Pressure variation throughout a thermodynamic cycle with crank angle

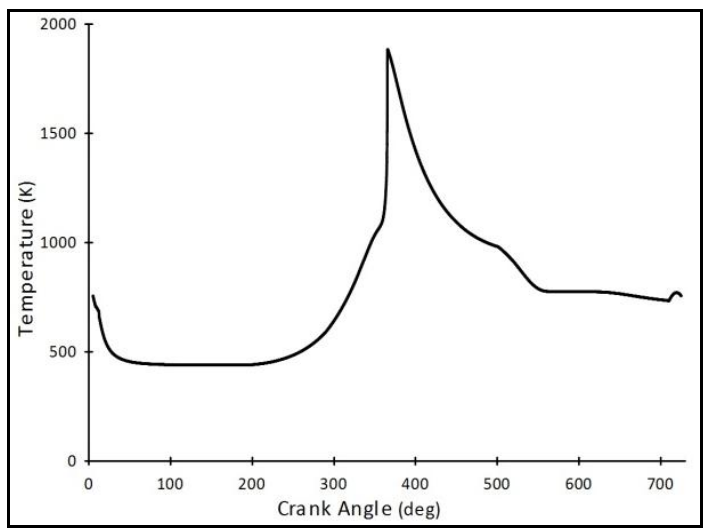

Fig. 5. Temperature variation with crank angle

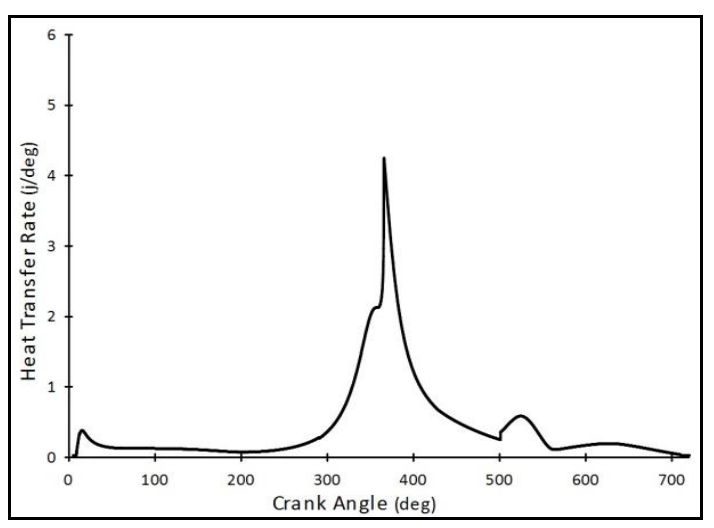

Fig. 6. Heat transfer rate variation with crank angle 
Figure 7 shows the variation of the components of the fuel with crank angle. The fuel, especially $\mathrm{CH} 4$ increases in the intake stroke. The sudden decrease of methane and other components of the fuel mass indicate the onset of combustion and the auto-ignition point and this shows that point can be used as a criterion to detect the auto-ignition and starting the combustion. The major pollutants produced in the cylinder due to oxidation of fuel are shown in Figs 8-10. The variations of all species have good consistency with chemical kinetic scheme implemented in modeling in overall. It was found that the $\mathrm{CO}$ value increased rapidly at the start of combustion, but after the combustion completion, the oxidation of $\mathrm{CO}$ had taken more speed and its concentration would therefore decrease. Also the $\mathrm{CO} 2$ concentration will increase through oxidation of $\mathrm{CO}$.

The nitrogen oxides (NOx) are important pollutants in internal combustion engines and the variation of nitrogen oxides (NOx) are shown in Fig.10.The NO concentration increases rapidly with starting of combustion due to increasing the temperature and its value freeze after taking the maximum value, so this is compatible with extended Zeldovich mechanism applied in this modelling which considers only thermal formation of NO. Also the $\mathrm{N} 2 \mathrm{O}$ and $\mathrm{NO}$ species have good prediction as shown in Fig.10.

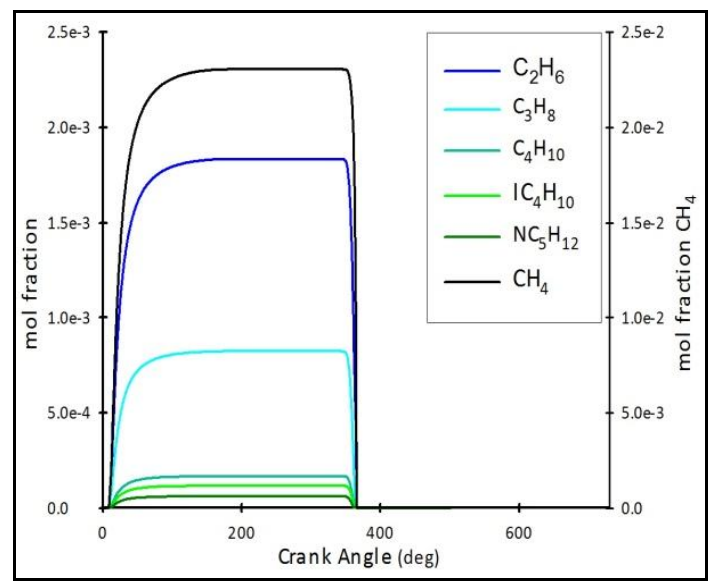

Fig. 7. Components of the fuel mass variation with crank angle

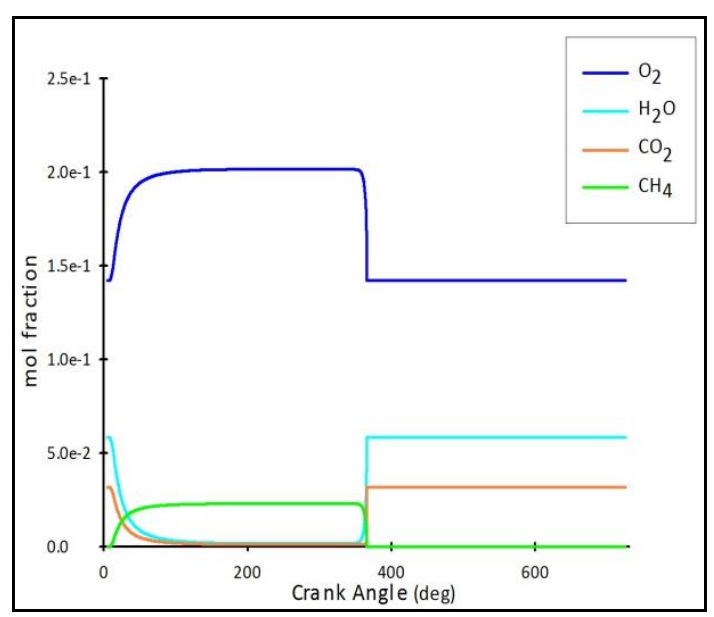

Fig. 8. In-cylinder important produced species with crank angle

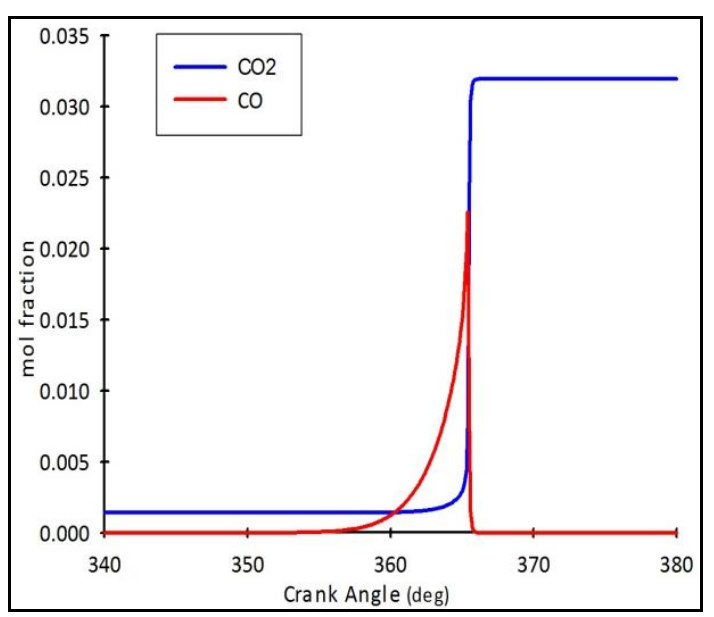

Fig. 9. The variation of $\mathrm{CO}$ and $\mathrm{CO} 2$ with crank angle

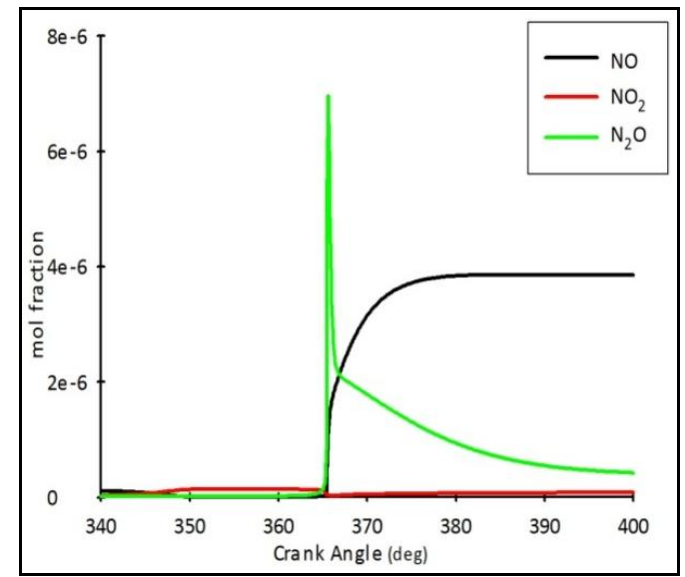

Fig. 10. Concentration of NO, N2O \& NO with crank angle

Several parametric studies of initial temperature, pressure, equivalence ratio, compression ratio and exhaust gas recirculation (EGR) were carried out using the complete cycle simulation and these studies are shown graphically in Figs. 11-25.The equivalence ratio is an important operating parameter and has more effects on performance and pollutants emission in internal combustion engines. The effects of this parameter on performance and pollutants variation are shown in Figs. 11, 12 and 13. With increasing the equivalence ratio, the pressure and temperature dependent pollutants such as NO increases and at the stoichiometric point, the concentration of NO take the maximum values due to higher combustion temperature at this condition. When the mixture is richer, the concentration of oxygen decreases, while the maximum temperature as well as the concentrations of NOx will decrease, whereas, with leaner mixture, the maximum temperature decreases. With increasing temperature and pressure at the start of compression stroke, the pressure and temperature of in- cylinder will increase and starting of combustion shifts to earlier and this is because the increasing of temperature will start the chemical reactions and onset of combustion finally. Also with high value of initial pressure and temperature NOx increases due to increasing the maximum incylinder temperature. 


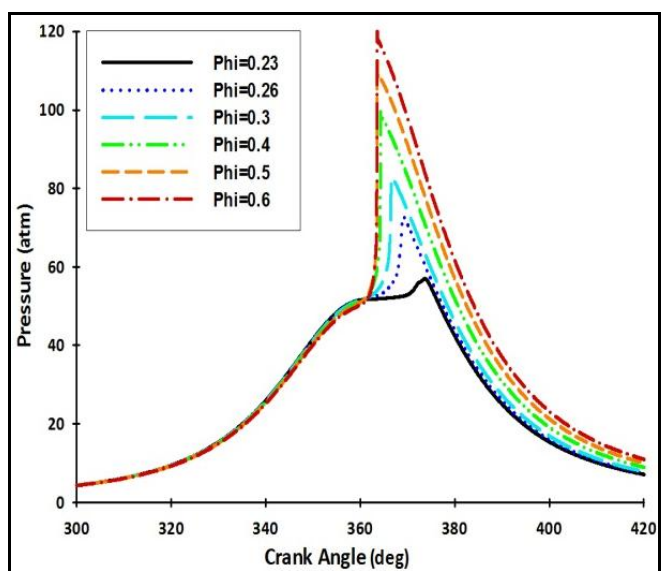

Fig. 11. Effect of Equivalence ratio on ignition and pressure

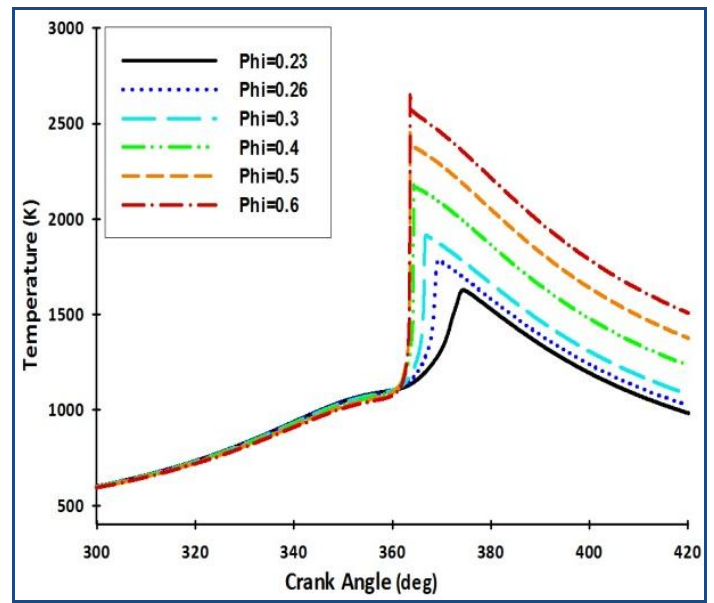

Fig. 12. Effect of Equivalence ratio on in-cylinder temperature

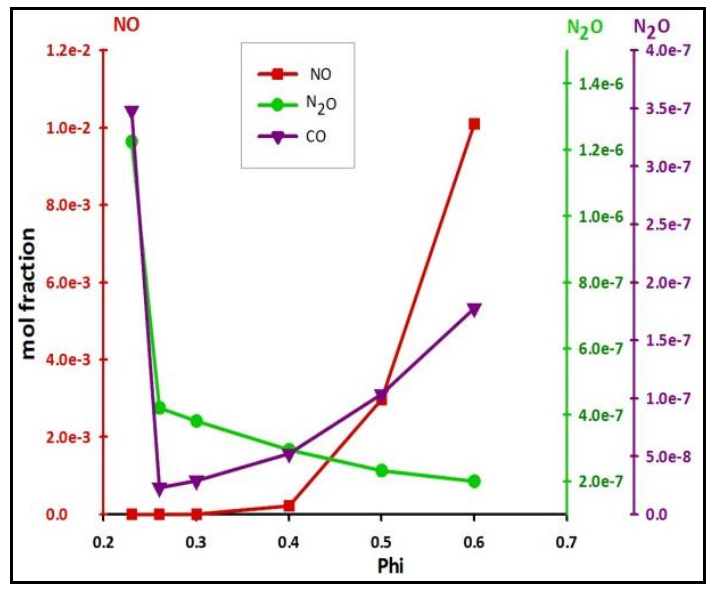

Fig. 13. Effect of Equivalence ratio on major pollutants variation

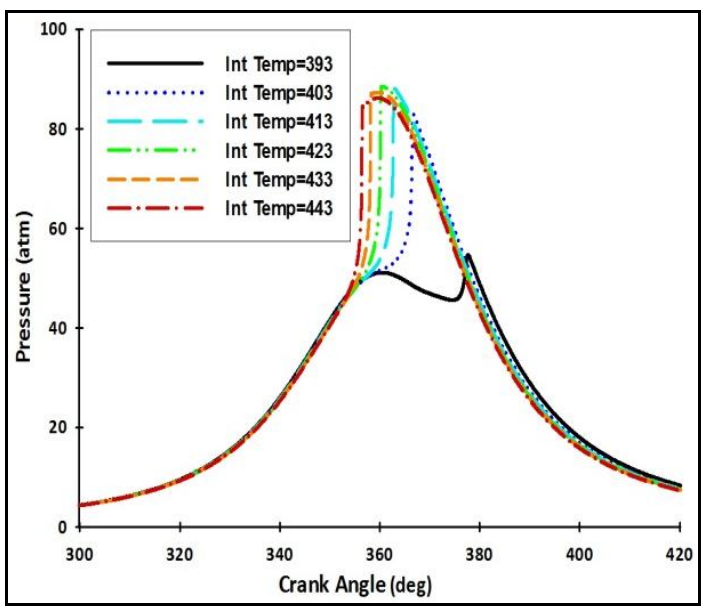

Fig. 14. Effect of intake charge temperature on ignition

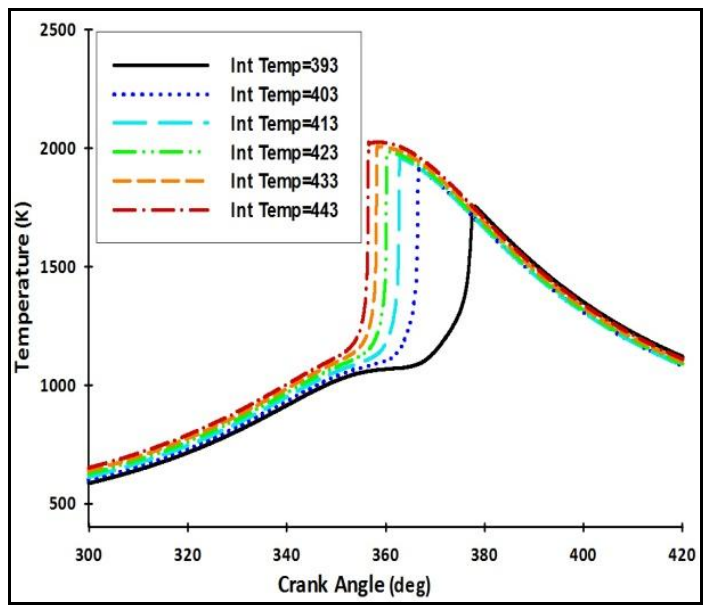

Fig. 15. Variation of in-cylinder temperature with crank angle at different intake temperatures

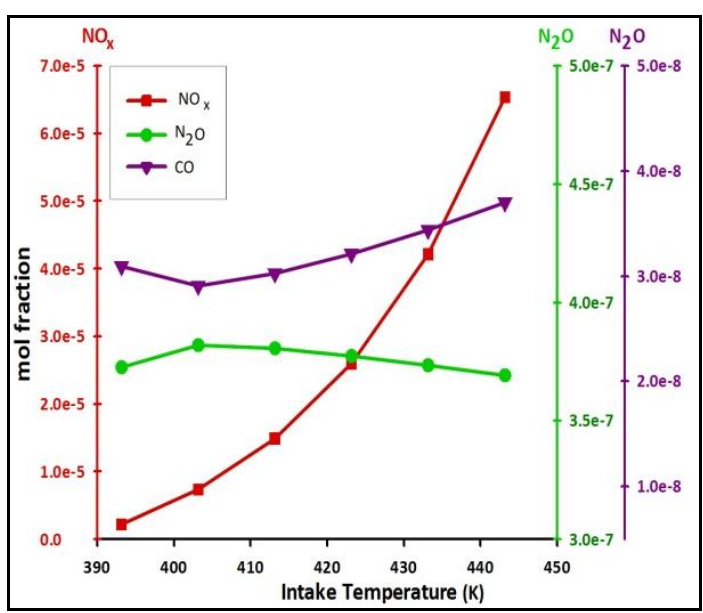

Fig. 16. Variation of pollutants emission with intake temperature

The effect of intake charge temperature and pressure on performance and pollutants emission are shown in Figs. 14-19. With increasing the intake charge temperature, the peak in-cylinder temperature will take higher values 
but it must be notified that the fuel mass and total heat released are constant for all intake temperature and the density and volumetric efficiency will decrease, but the effect of it is less. The intake temperature effect on pollutants is shown in Fig. 16, and with increasing the intake temperature, the maximum value of temperature and so the pollutants are increased. The pressure effects are similar with temperature and are shown in Figs. 17, 18 and 19 . With increasing the intake charge pressure, the in-cylinder temperature, in-cylinder pressure and dependent pollutants are increased.

Another important operating parameter for internal combustion engines at optimum working is the exhaust gas recirculation (EGR) which is used for control of pollutants emission.EGR involves the gases from cylinder combustion products such as $\mathrm{CO} 2, \mathrm{CO}, \mathrm{NO}$, $\mathrm{H} 2 \mathrm{O}$, and so on. These gases have important role in changing the specific heat capacity of intake charge mixture and thus for control of initial temperature and pressure of cylinder. The effects of EGR on performance and pollutants of HCCI engine are shown in Figs. 20, 21 and 22. Increasing the exhaust gas recirculation (EGR) value, will cause the shift of onset of combustion to earlier due to increasing the temperature, but the effect of EGR on temperature and pressure increasing, is less than the other parameters because, with increasing the EGR, the total molecular weight of mixture will increase and this results the increasing of heat capacity of mixture. Also with increasing the EGR value near to optimum value, will result the decreasing of $\mathrm{NO}$ and $\mathrm{CO}$. It must be notified that the operation of engine with non-optimum value of EGR will result the increasing of major pollutants.

The compression ratio (CR) parameter is using for control of onset of knock in internal combustion engines and it is an important parameter in designing of an internal combustion engine. Also, it is a key parameter in increasing the engine efficiency but its value is limited by knock phenomena. The effects of compression ratio on performance and pollutants are shown in Figs. 23, 24 and 25. With increasing the CR, the pressure and temperature increases and the onset of combustion (starting of chemical reaction) will shifts to earlier on crank angle axis, also with increasing the CR, NOx pollutants increase due to temperature increasing but the $\mathrm{CO}$ emission change very slowly.

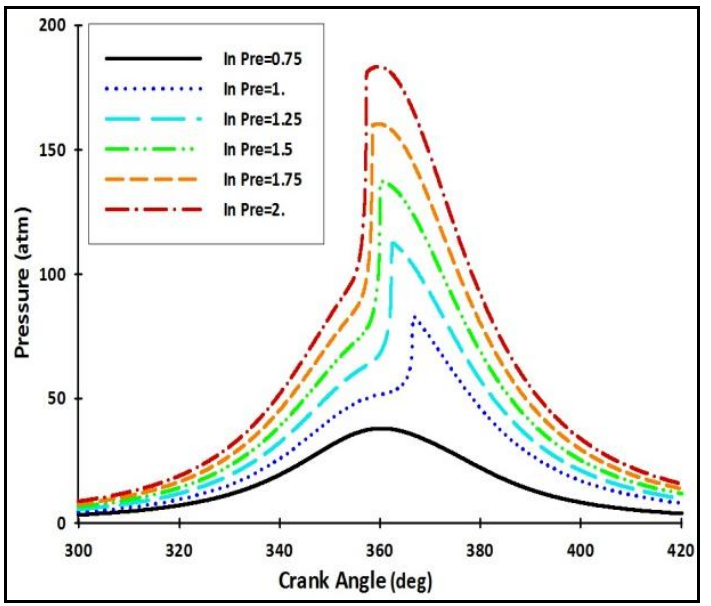

Fig. 17. Effect of intake charge pressure on ignition

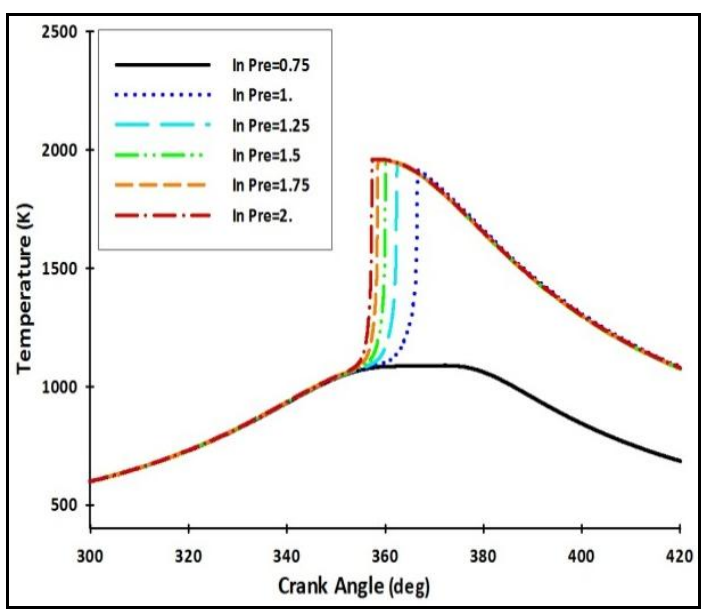

Fig. 18. Effect of intake charge pressure on in-cylinder temperature

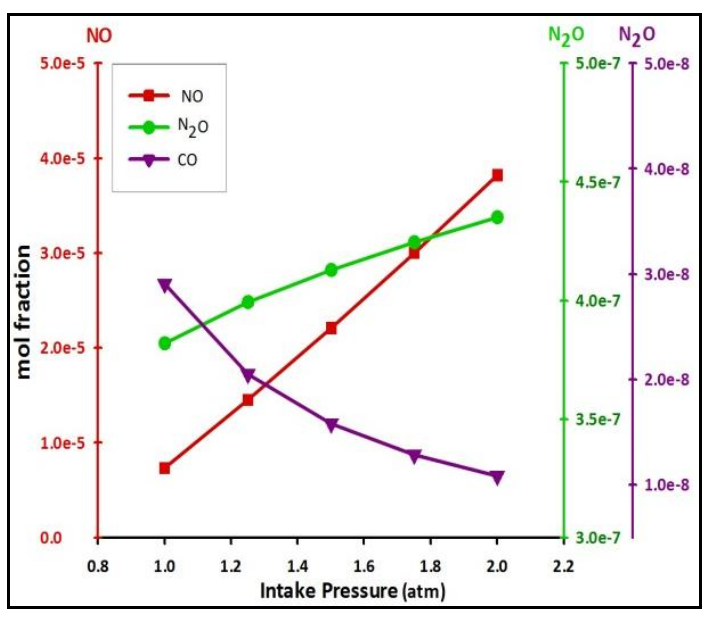

Fig. 19. Effect of intake charge pressure on pollutant

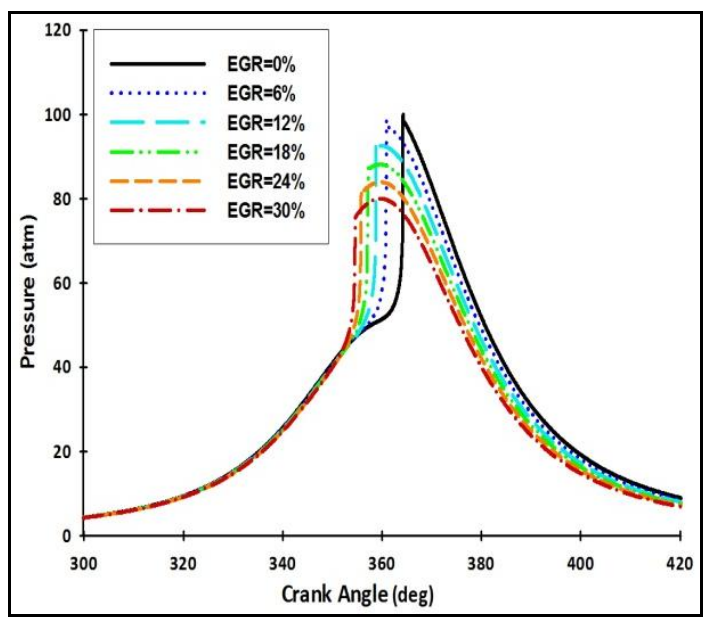

Fig. 20. Pressure variation with crank angle at different EGR values 


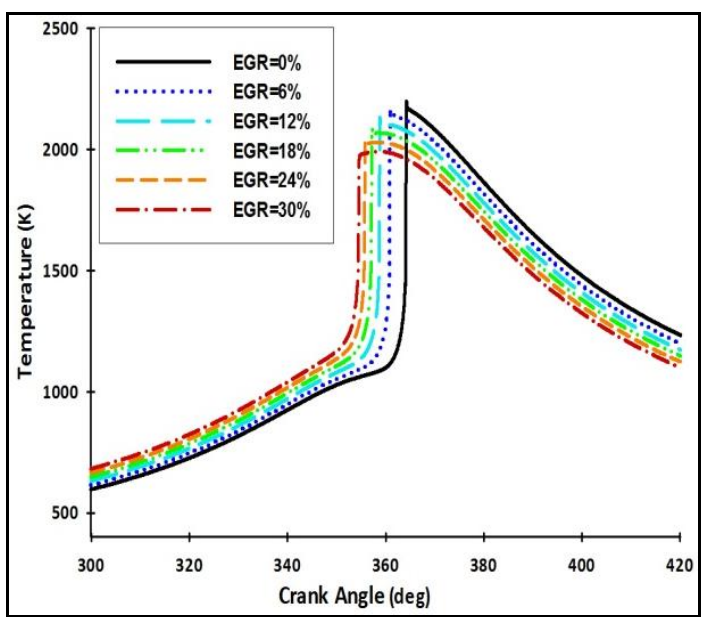

Fig. 21. Temperaure variation with crank angle at different EGR values

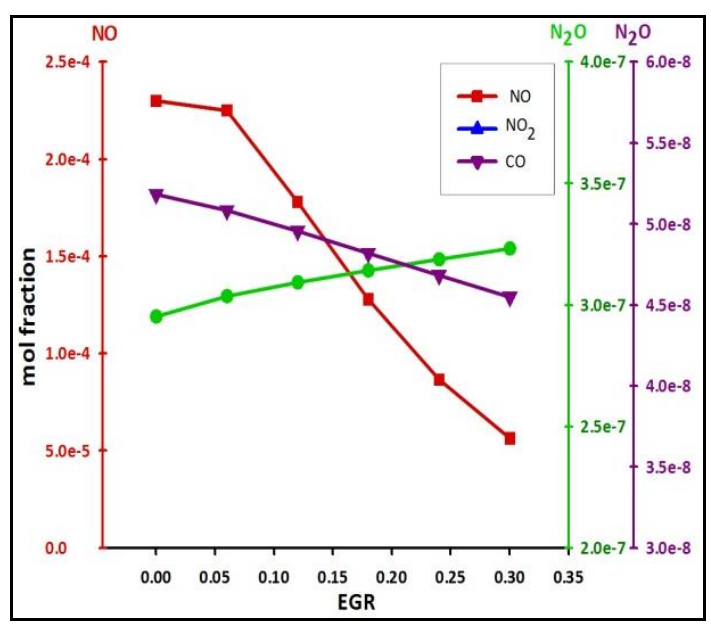

Fig. 22. Effect of EGR on pollutants

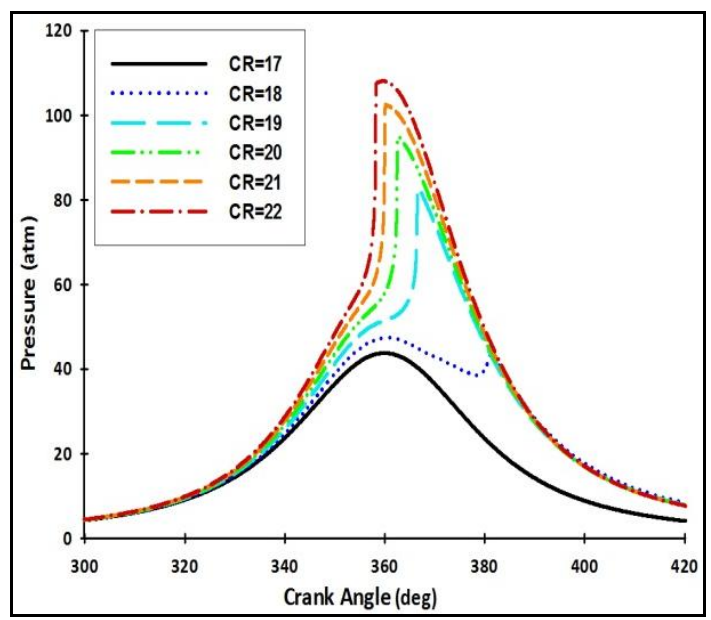

Fig. 23. Pressure variation with crank angle at different compression ratio

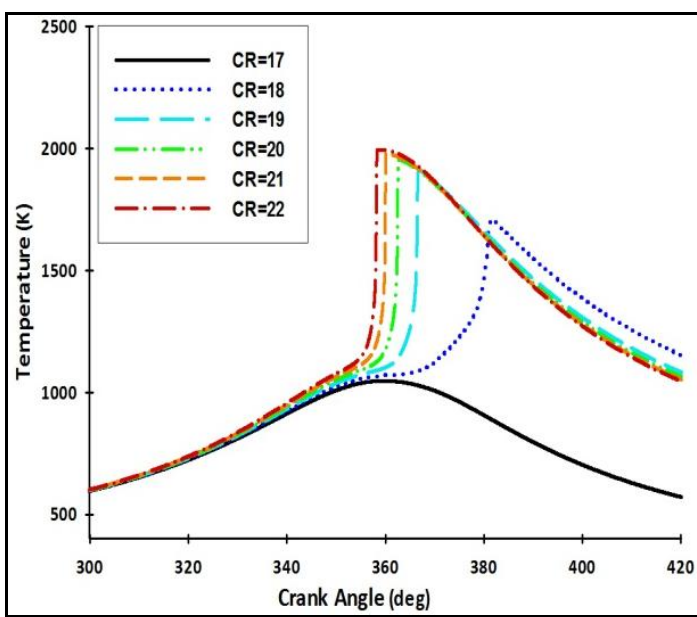

Fig. 24. Temperature variation with crank angle at different compression ratios

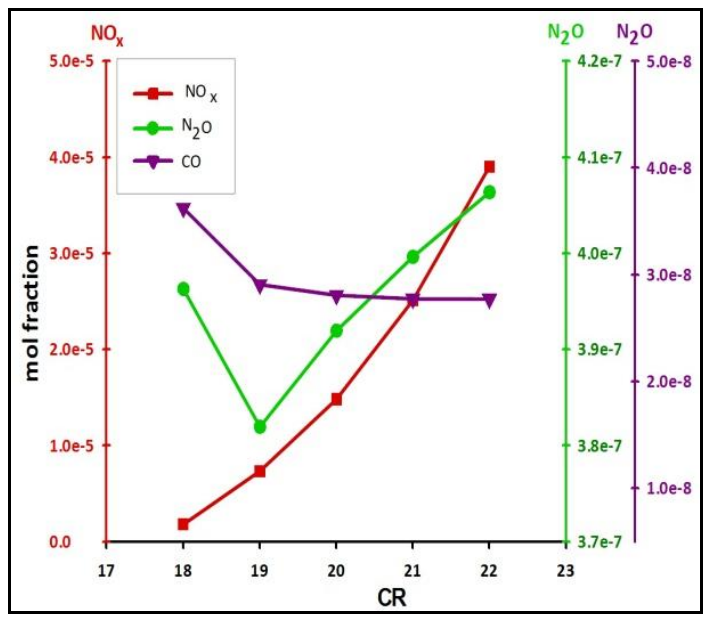

Fig. 25. Effect of compression ratio on pollutants

\section{CONClusion}

An in-house quasi-dimensional code has been developed which simulates the processes of a Homogeneous Charge Compression Ignition (HCCI) engine. It couples with a detailed chemical kinetic scheme which involves the multi-reactions equations. The chemical kinetic scheme developed here, contains 1701 elementary reactions and 310 species. The effects of parameters such as initial temperature, initial pressure, engine speed, compression ratio and equivalence ratio on the combustion characteristics and performance and pollutants emission of CNG fuelled HCCI engine have been studied. The extracted results show good agreement with experimental data.

\section{REFERENCES}

Agrawal, A. and D.N. Assanis (1998). Multidimensional modeling of natural gas ignition under compression ignition using detailed chemistry. SAE International Technical Papers 980136. 
Bakhshan, Y. and S. Abdullah (2009). Study of CNG Combustion under Internal Combustion Engines Conditions. Part I: Using of Quasi-Dimensional Modeling. Algerian Journal of Applied Fluid Mechanics, Vol. 1, 1-9

Hong, S., M. Woold Ridge and D.N. Assanis (2002). Modeling of Chemical and Mixing Effects on Methane Auto Ignition Under Direct Injection Stratified Charge Conditions. Proceeding of the 29th International Symposium on Combustion, Vol.29(1), 711-718

Ishibashi, Y. and M. Asai (1996). Improving the Exhaust Emissions of Two-Stroke Engines by Applying the Activated Radical Concept. SAE International Technical Papers 960742.

Kee, R. J., F. M. Rupley and J. A. Miller (1996). CHEMKIN-II: A FORTRAN Chemical Kinetics Package for the Analyses of Gas Phase Chemical Kinetics. Sandia National Laboratory Report, SAND 89-8009.

Kimura, S., O. Aoki, H. Ogawa, S. Muranaka and Y. Enomoto (1999). New Combustion Concept for Ultra-Clean and High-Efficiency Small DI Diesel Engines. SAE International Technical Papers 199901-3681.

Kong, S., C.D. Marriott, C.J. Rutland and R.D. Reitz (2002). Experiments and CFD Modeling of Direct Injection Gasoline HCCI Engine Combustion, SAE International Technical Papers 2002-01-1925.

Mansouri, S. H. and Y. Bakhshan (2000). The k-epsilon Turbulence Modeling of Heat Transfer and Combustion Processes in a Texaco Controlled Combustion Stratified Charge Engine. Journal of Automobile Engineering 214(2), 149- 158.
Mansouri, S. H., and Y. Bakhshan (2001). Studies of Nox, CO, Soot Formation and Oxidation from Direct-injection Stratified-Charge Engine Using kepsilon Turbulence Model. Journal of Automobile Engineering 215, 95-104.

Najt, P.M. and D.E. Foster (1983). Compressionignited homogeneous charge combustion. SAE International Technical Papers 830264.

Noguchi, M., Y. Tanaka, T. Tanaka and Y. Takeuchi (1979). A study on gasoline engine combustion by observation of intermediate reactive products during combustion. SAE International Technical Papers 790840 .

Onishi, S., S. Hong Jo, K. Shoda, P. Do Jo and S. Kato (1979). Active Thermo- Atmosphere Combustion (ATAC) - A new combustion process for internal combustion engines. SAE International Technical Papers 790507.

Ryan, T.W. and T.J. Callahan (1996). Homogeneous Charge Compression Ignition of Diesel Fuel. SAE International Technical Papers 961160.

Pascal, S. (2011). Hot Air Engines. Journal of Applied Fluid Mechanics (JAFM) 4 (2), 1-8.

Patel, A., S. C. Kong, R. D. Reitz (2004). Development and Validation of a Reduced Reaction Mechanism for HCCI Engine Simulations. SAE paper 2004-01-0558.

Yao, M. F., C. Huang, Z. L. Zheng (2007). Multidimensional Numerical Simulation on dimethyl ether/methanol Dual Fuel HCCI Engine Combustion and Emission Processes. Energy Fuel, 21(2), 812-21. 